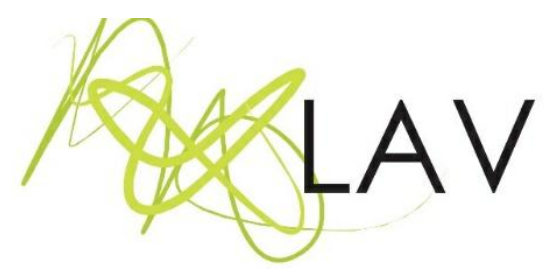

\title{
Experiência Multissensorial: Uma Proposta para Alunos com Deficiência na Perspectiva da Educação Inclusiva
}

Multisensory Experience: A Proposal for Students with Disabilities from the Perspective of Inclusive Education

\author{
Cleane da Silva Nascimento \\ Universidade Federal de Roraima \\ Luís Müller Poscaii \\ Universidade Federal de Roraima \\ Paulo Sérgio Marotiii \\ Universidade Federal de Roraima
}

\section{Resumo}

A presente pesquisa tem como objetivo verificar as potencialidades do vídeo mapping como recurso de ensino de artes para as pessoas com deficiência. Para tanto, busca-se pensar estratégias que possibilitem novos modelos de aprendizagens baseados na sociedade da informação, consolidada na motivação entre professores e alunos de transformarem as potencialidades desses recursos em aprendizagem. Cabe destacar a necessidade de incluir os alunos com deficiência no processo de ensino/aprendizagem da disciplina de Artes. O processo deve ocorrer de modo cooperativo e autônomo, promovendo a Educação Inclusiva, um direito destes indivíduos, garantido pela Lei de Diretrizes e Bases no 9.394/96 e fortalecido pela Lei no 13.146, de 6 de julho de 2015. Para a realização deste trabalho, faz-se uso da revisão bibliográfica do tipo integrativa. Os resultados visam corroborar para superar lacunas da Educação Especial inclusiva no Estado de Roraima. Neste caso, as TIC mostram-se como um instrumento eficaz para o ensino de Artes Visuais.

Palavras-chave: Ensino de Arte, Ensino-Aprendizagem, Educação Inclusiva, TIC, Vídeo Mapping.

Enviado em: 03/06/20 - Aprovado em: 29/06/21

\section{Abstract}

This research aims at verifying the potential of video mapping as an arts teaching resource for people with disabilities. To this end, we seek to think of strategies that enable new models of learning, based on the information society, consolidated in the motivation between teachers and students to transform the potential of these resources into learning. It is worth highlighting the need to include students with disabilities in the teaching/learning process of the Arts subject. The process must take place in a cooperative and autonomous way, promoting inclusive education, a right of these individuals, guaranteed by the Law of Guidelines and Bases no 9.394 / 96 and strengthened by the Law no 13.146, of July 6, 2015. For this work, we used the

Revista Digital do LAV - Santa Maria - vol. 14, n. 3, p. 67 - 82 - set./dez. 2021 ISSN 1983 - 7348 http://dx.doi.org/10.5902/1983734846865 
integrative literature review. The results aim at corroborating to overcome gaps in special inclusive education in the State of Roraima. In this case, ICT is shown as an alternative for the teaching of Visual Arts.

Keywords: Art Teaching, Teaching-Learning, Inclusive Education, ICT, Video Mapping.

\section{Introdução}

As Tecnologias da Informação e Comunicação (TIC) surgiram em meados da década de 90 e se mostram como potentes para (des)construção de práticas pedagógicas para o ensino de Artes Visuais, oferecendo um ensino inovador capaz de adentrar em espaços educativos, sendo uma alternativa por meio de uma proposta diferenciada.

Desse modo, o presente trabalho propõe verificar as potencialidades do vídeo mapping ${ }^{1}$ como recurso de ensino de artes para as pessoas com deficiência. Buscamos compreender como a escola atual utiliza e incentiva o uso das TIC, em especial o video mapping para alunos com deficiência, e como essa ferramenta pode proporcionar autonomia para o usuário, permitindo uma aula diferenciada e inovadora, interligando arte, educação e tecnologias contemporâneas.

Neste sentido, recorremos a estratégias que propõem uma ferramenta baseada nas TIC, possibilitadoras de inovação e instigante para os alunos na busca de novos conhecimentos. Utilizamos o vídeo mapping por permitir aos usuários uma experiência com efeitos de ilusão de ótica, podendo também serem inseridos efeitos sensoriais.

A presente pesquisa é de cunho qualitativo, uma vez que busca compreender um determinado grupo social. Buscamos dar um retorno direto a população, destacando o processo de ensino/aprendizagem e o desenvolvimento cultural. A revisão bibliográfica foi realizada cuidadosamente a partir da utilização de documentos de repositórios da Coordenação de Aperfeiçoamento de Pessoal de Nível Superior (CAPES), Scientific Electronic Library Online (SCIELO), dentre outros, sempre pautando na originalidade e segurança, primando pela qualidade do trabalho. A escolha se deu pelas bases reunirem pesquisas relevantes tanto em âmbito nacional, quanto internacional. Para tanto, realizaram-se como critérios as palavras-chave: Educação Especial, Educação Inclusiva, TIC e Vídeo Mapping. Além disso, utilizamos como recorte temporal pesquisas a partir do ano de 2008, quando entrou em vigor a Política Nacional de Educação Especial na Perspectiva da Educação Inclusiva no Brasil.

\footnotetext{
1 Técnica de projeção de luz numa estrutura tridimensional, a qual é previamente mapeada por um software (GARCIA, 2014).
}

Revista Digital do LAV - Santa Maria - vol. 14, n. 3, p. 67 - 82 - set./dez. 2021 ISSN 1983 - 7348 http://dx.doi.org/10.5902/1983734846865 


\section{A Poética da (Re)Construção e Visualização da Arte para Pessoas com Deficiência}

A Educação Especial é uma modalidade de ensino transversal que visa o ensino/aprendizagem à alunos com deficiência. Estão contempladas as pessoas com "impedimento a longo prazo de natureza física, mental, intelectual ou sensorial, a qual, em interação com uma ou mais barreiras, pode obstruir sua participação plena e efetiva na sociedade em igualdade de condições com as demais pessoas" (BRASIL, 2015, p. $\mathrm{s} / \mathrm{n})$.

É assegurada no Brasil, desde a Constituição Federal de 1988 por meio do art. 205, a educação para todos, sem distinção por qualquer especificidade apresentada. Todavia, este elemento não foi suficiente para assegurar a inclusão de alunos com deficiência nas escolas.

Somente no ano de 1996, com a Lei de Diretrizes e Bases da Educação Nacional (LDBEN) 9.394/1996 que foi assegurado apoio especializado na escola regular para os alunos com deficiência. É quando percebemos que, embora a educação seja um direito de todos, sem distinção, na prática ainda não é uma realidade. Quando destacamos esse elemento, percebemos as mudanças ocorridas desde a promulgação da Constituição Federal de 1988 até os dias atuais, pois, na atualidade os alunos com deficiência já podem adentrar nas escolas, entretanto, ainda se faz necessário criar estratégias para o processo de ensino/aprendizagem no âmbito da Educação Inclusiva.

A Educação Inclusiva ocorre quando são inseridos todos os alunos no espaço educacional, permitindo

[...] um espaço democrático e competente para trabalhar com todos os educandos, sem distinção de raça, classe, gênero ou características pessoais, baseando-se no princípio de que a diversidade deve não só ser aceita como desejada (BRASIL, 1999, p. 40).

No entanto, dentro desta perspectiva, é necessário respeitar as particularidades dos alunos com deficiência, dando-Ihes subsídios para uma educação de qualidade.

Assim, se mostra plausível a reorganização do sistema educacional na perspectiva inclusiva, apontando novos caminhos para a escola, a partir de um novo modelo de formação docente que busque um professor preparado para atuar com o auxílio das TIC,

Revista Digital do LAV - Santa Maria - vol. 14, n. 3, p. 67 - 82 - set./dez. 2021 ISSN 1983 - 7348 http://dx.doi.org/10.5902/1983734846865 
criando novos métodos tecnológicos, os quais proporcionem um novo tipo de aprendizado, baseado na sociedade da informação.

Apesar da concepção da evolução tecnológica como real e necessária, as escolas encaram a inserção das TIC como um desafio a ser superado, em particular as escolas brasileiras. Isso ocorre, principalmente, pela falta de professores capacitados para o uso das TIC e não pela falta de acesso a informação ou às próprias tecnologias que permitem o acesso.

Entende-se por TIC um coletivo tecnológico integrado em prol de um mesmo objetivo. Para Barroso e Escola (2011):

[...] as TIC podem ser consideradas um dos fatores mais importantes para as profundas mudanças no mundo e, com a dinâmica da inovação, tornam-se imprescindíveis para a economia global e seu desenvolvimento (BARROSO; ESCOLA, 2011, p. 151).

O campo aponta possibilidades inovadoras por meio do cenário virtual, como uso de recursos pedagógicos alternativos e promissores para o ensino de Artes Visuais, considerando as condições e infraestrutura disponíveis nos laboratórios e a realidade vivida pelos alunos. Uma das dificuldades para o uso das TIC na educação diz respeito a dificuldade no manuseio, porém, esta situação tem se modificado após o cenário da pandemia causada pelo vírus SARS-COV2.

Ousamos salientar que ao defender o uso das TIC no ambiente escolar para alunos com deficiência diante da sociedade da informação, não buscamos o abandono de todas as metodologias já utilizadas pelos professores, mas a incorporação das TIC sempre que necessário, por serem ferramentas capazes de enriquecer o nosso cotidiano, pensando principalmente no novo perfil de alunos que temos.

Segundo o Livro Verde (2000, p. s/n) "no Brasil, Governo e sociedade devem andar juntos para assegurar a perspectiva de que seus benefícios efetivamente alcancem a todos os brasileiros". Além do que, a sociedade contemporânea convive com transformações científicas, tecnológicas, políticas e incertezas em escalas imprevisíveis em todos os setores, inclusive no que diz respeito ao conhecimento e sua excessiva fragmentação. Atualmente, o cenário vivido exige capacidade para pensar o significado da mudança nesta sociedade, de modo a compreender uma estratégia para que a escola se adeque a nova realidade civilizatória (ESCOLA, 2005).

De acordo com Escola (2005): 
[...] a informática profetizou a capacidade de pensar por nós e de forma mais rápida, mas que até ao presente, com raríssimas exceções, disponibilizou exemplos de como se podia atrofiar a memória, o juízo ou a criatividade (ESCOLA, 2005, p. 346).

Partindo desse pressuposto e respeitando as diferenças e singularidades de uma Educação Inclusiva, percebemos que nada se constrói fora da vertente pós-moderna de imersão tecnológica, e as práticas cotidianas se tornam cada dia mais expressivas através dos aparatos eletrônicos. Segundo Posca (2017),

[...] fora do âmbito educacional, instituições, museus e ONGs estão utilizando recursos tecnológicos para promover ações ou exposições no sentido de incluir o deficiente visual no mundo das Artes Visuais (POSCA, 2017, p. 14).

Isso, por conseguinte, aponta para evolução dos saberes, tornando legítimo o debate em torno das necessárias 'transformações de mentalidades', dentro e fora do espaço educacional, na qual se observa o surgimento de uma cultura convergente, transdisciplinar, multireferencial, criativa e tecnológica, o que se impõe como um forte desafio ao papel da ciência para a criação de novos modos de convivência com os saberes.

Nessa perspectiva, o uso das TIC se mostra pertinente no campo da Educação Inclusiva, partindo do pressuposto da permissão de um aprendizado por meio de uma metodologia diferenciada. Os fatores que contribuem para isso são inúmeros, entre os quais podemos destacar que os alunos de hoje, do maternal a faculdade, passam grande parte do dia fazendo uso das tecnologias (PRENSKY, 2001). Além disso, as TIC podem diminuir o individualismo, pois a "sociedade do conhecimento exige - se a participação e cooperação com os outros, o reconhecimento do valor ao pluralismo, da cooperação mútua, da paz" (ESCOLA, 2005, p. 352).

Segundo Lemos e Silva (2011, p. 36), "uma coisa é certa, as crianças e adolescentes da era digital parecem já nascer aptas a interagir com e nesses meios e, a partir deles construir suas relações". Partindo desse pensamento, percebemos como o campo permite ao professor criar estratégias que promovam a inclusão a partir do uso das TIC, sendo um ponto positivo em relação aos objetivos da Educação Inclusiva.

Com o uso das TIC, o professor pode se valer de ferramentas visuais e sonoras, conforme é destacado por Paim (2011), e com esses meios é capaz de desenvolver o conhecimento de uma criança com recursos educacionais limitados para intensificar o processo de ensino/aprendizagem. 
Contudo, é necessário enfatizar as inserções das TIC acompanhadas por metodologias adequadas, pois as ferramentas por si só não são capazes de proporcionar os resultados esperados. Assim, um dos enfoques principais desta pesquisa é refletir sobre como as TIC promovem a aprendizagem por etapas e de maneira interativa, rompendo as dificuldades de aprendizado na medida em que o conhecimento aconteça.

Para além disso, é preciso ter atenção em como ocorre a interação dos alunos ao fazer uso destes recursos, e a partir disso, propor sugestões e alternativas para o seu uso na educação brasileira, em especial no campo da Educação Especial.

É cabível também observar como as TIC vem provocando vários campos socioculturais a refletirem sobre as transformações, a partir dos jogos digitais, ambientes virtuais imersivos, redes sociais, dentre outras ferramentas, desafiando todos os intervenientes a encontrarem novas possibilidades de se adaptarem às mais recentes exigências que irrompem no seio da sociedade e se plasmam nos diferentes setores (ESCOLA, 2005).

\section{Vídeo Mapping e suas Possibilidades na Educação Inclusiva}

O video mapping ou projeção mapeada é uma técnica que visa a expressão comunicativa a partir do uso de recursos tecnológicos. Trata-se de uma projeção com animações cinematográficas, videográficas ou computacionais em superfícies internas e externas. É uma experiência multisensorial que envolve imagem e som. Suas características são: animação gráfica, elementos bidimensionais (2D), tridimensionais (3D) e ilusão de ótica (GARCIA, 2014).

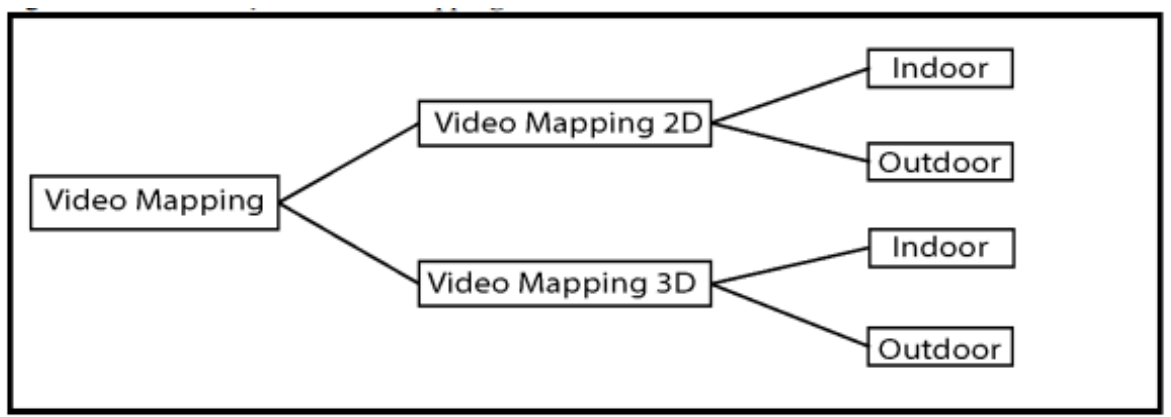

Figura 1: Classificação de Vídeo Mapping.

Fonte: GARCIA, 2014.

Revista Digital do LAV - Santa Maria - vol. 14, n. 3, p. 67 - 82 - set./dez. 2021 ISSN 1983 - 7348 


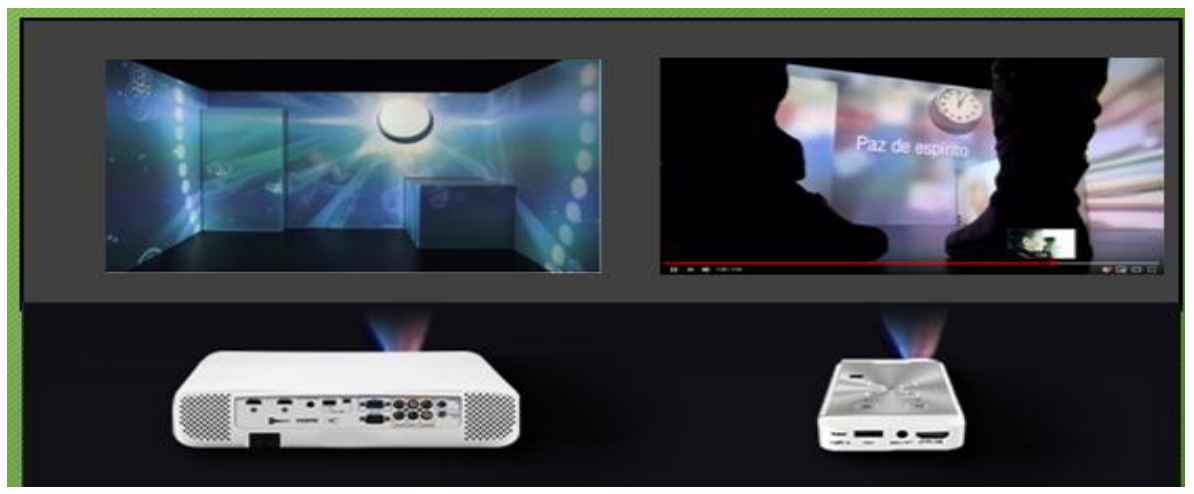

Figura 2: Projeto de projeção do Vídeo Mapping. Fonte: Elaborado pela autora, 2019.

O vídeo mapping se tornou popular a partir do suporte nos programas de vjing (video jockey). Estes programas são responsáveis pela criação e pela manipulação de imagens artísticas, sicronizados com som em tempo real. "É conhecido como uma técnica, mas podemos perceber seu potencial poético nos trabalhos desenvolvidos e nas reflexões dos autores que estudam o tema" (MORAES, 2014, p. 16).

Segundo Garcia (2014),

As técnicas de projeções mapeadas também podem ser divididas em: projeção indoor (interna) e projeção outdoor (externa), sendo a primeira, projeções realizadas dentro de um ambiente real controlado, como uma sala, um galpão ou um estúdio; a segunda são projeções realizadas em ambientes reais externos, como os cenários urbanos: fachadas de prédios, árvores, paredes, ou mesmo superfícies específicas para essa finalidade (GARCIA, 2014, p. 12).

A técnica utilizada para criação do vídeo mapping não é baseada apenas em um programa específico. Podem ser usadas técnicas variadas, a partir de diversos softwares: blender, photoshop, 3D Max, Adobe After Effects, entre outros. Assim, são realizadas diversas combinações que possuem efeitos audiovisuais, posteriormente executadas com um programa vjing.

O programa vjing indicado para a realização desta experiência nas escolas é o VPT, por ser gratuito e funcionar tanto no Windows como no MAC OS. Por ser um programa gratuito, possui suas limitações, porém, é intuitivo, de modo a não necessitar de aprofundamento técnico para o seu uso.

Percebemos a necessidade de adequar as tecnologias de acordo com o nosso propósito. Esta é uma necessidade básica nos dias atuais. E o video mapping é uma tecnologia utilizada em todo o mundo para finalidades artísticas, publicitárias, para 
entretenimento, dentre outras. Então, partindo do pressuposto de que elas são eficazes para a realização de tarefas, trataremos aqui de seu uso como uma ferramenta para o ensino de Artes Visuais na perspectiva da Educação Inclusiva.

Destacamos que superar as lacunas apresentadas na educação é um desafio diário. Assim, é necessário apresentar ferramentas que permitam apontar desafios e a partir deles refletir sobre as possibilidades de (re)construção de saberes na Educação Inclusiva.

O vídeo mapping apresenta possibilidades a partir das imagens, movimento, som e imersão. As imagens têm por objetivo "comunicar, representar e informar" (LIMA; SANTOS, 2009, p. 405). Estes autores defendem que:

$\mathrm{Na}$ modernidade, os modos de produção de imagem romperam definitivamente os modos anteriores. Os aparatos técnicos e químicos de produção de imagem possibilitaram a captura de imagens do mundo real de modo muito mais rápido (LIMA; SANTOS, 2009, p. 405).

Defendemos que a imagem é inerente para a construção do mundo, bem como para o desenvolvimento cognitivo do ser humano. Portanto, apresentamos como alternativa de leitura da imagem o processo de leitura criado por Abigail Housen (2000). Trata-se de uma integração entre o ler e o refletir a obra de arte, levando o observador, nesse caso o aluno, a pensar e verbalizar sobre a imagem. Os estágios de aprendizagem são voltados à apreciação estética e não a hierarquização por idade, tendo em vista a teoria ter sido pensada para observadores principiantes (HOUSEN, 2000).

Desdobramos então esta abordagem para a imagem em movimento. Essa possibilidade requer do aluno uma compreensão mais cuidadosa, haja vista que ele sai da imagem fixa - sem movimento - para a imagem em movimento e precisa ter seu olhar educado a fim de significá-la e ressignificá-la.

O som é uma forma de prender a atenção do aluno. Destacamos nesse caso a sonoplastia, que é um conjunto de efeitos sonoros trabalhados coletivamente com a imagem. Não obstante, nos debruçamos na imersão. Sua ocorrência no vídeo mapping acontece a partir da ilusão de ótica, da multisensorialidade e da sinestesia, pois durante a experiência é possível lançar aromatizantes de acordo com a atividade realizada, permitindo ao aluno sentir cheiros. Por exemplo, para uma atividade relacionada à artista Frida Kahlo, pode se utilizar aromas de flores. Neste caso, ressaltamos a experiência inovadora de construção de um saber com a 'imagem' para um aluno com deficiência visual, através de um outro canal sensorial. Aos que nasceram sem a visão, a 
possibilidade sinestésica aguçam a sua imaginação no sentido da criação e aos que já foram videntes, aguçam sua memória de modo a levá-los a relembrar uma sensação.

Todas estas possibilidades na mesma ferramenta poderiam prender a atenção do aluno e levá-lo ao aprendizado de maneira objetiva. E, embora a escola já reconheça a necessidade de utilizar as tecnologias como recursos educacionais, seu uso ainda não é uma realidade. Moreira (2006) destaca para a aprendizagem algumas condições, como: interesse, motivação, habilidades e a interação com diferentes contextos.

Desse modo, o desafio dos educadores na perspectiva da Educação Inclusiva é criar possibilidades que permitam ao aluno desenvolver o processo criativo, e a partir desses elementos promover a interação entre os alunos com e sem deficiência, buscando efetivar a Educação Inclusiva garantida pela Lei no 13.146, de 6 de julho de 2015 e pela Política Nacional de Educação Especial, na Perspectiva da Educação Inclusiva.

Para a criação de um vídeo mapping ou projeção mapeada é necessário uma visita ao espaço, uma vez que antes de produzir o conteúdo se faz necessário definir as características do local, elaboração do roteiro e modelagem da estrutura. A avaliação da luminosidade é fundamental para a compreensão do material a ser utilizado.

Logo após, para a criação do conteúdo é utlizado um software apropriado para criar as animações. Então, é realizada a montagem da estrutura, podendo ser com o uso de um projetor comum, utilizado em sala de aula, com 3200 ansi, cobrindo até 300 pol., ou mais ou menos 7,7 metros na horizontal. O planejamento acontece de acordo com a figura 3:

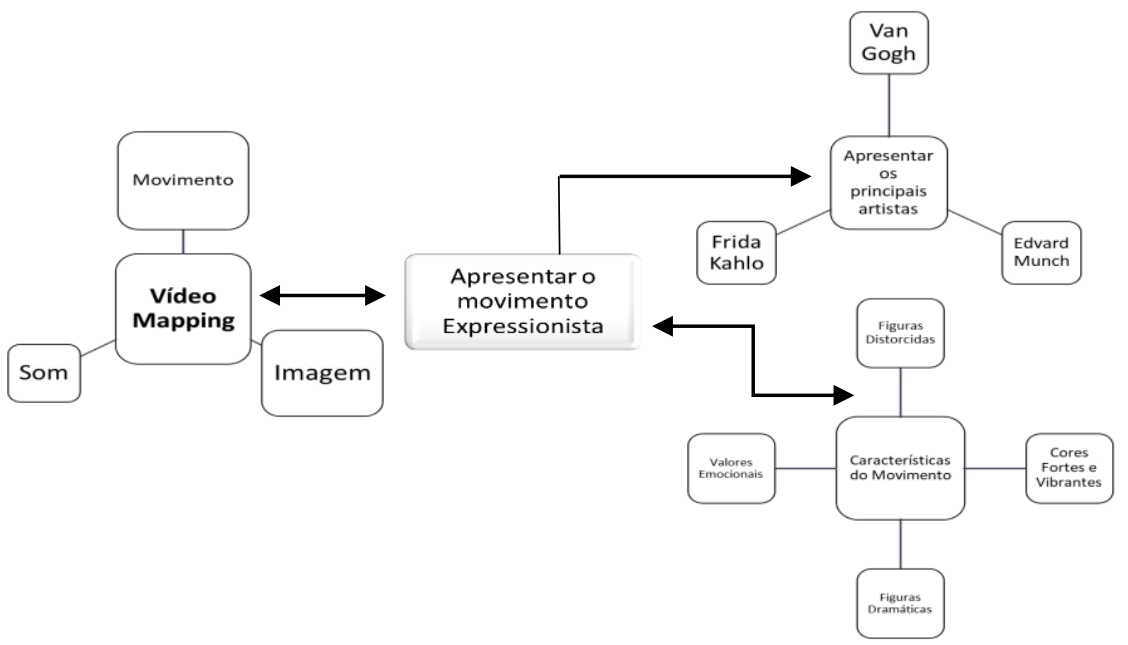

Figura 3: Modelo de criação de um video mapping. Fonte: Elaborado pela autora, 2019. 


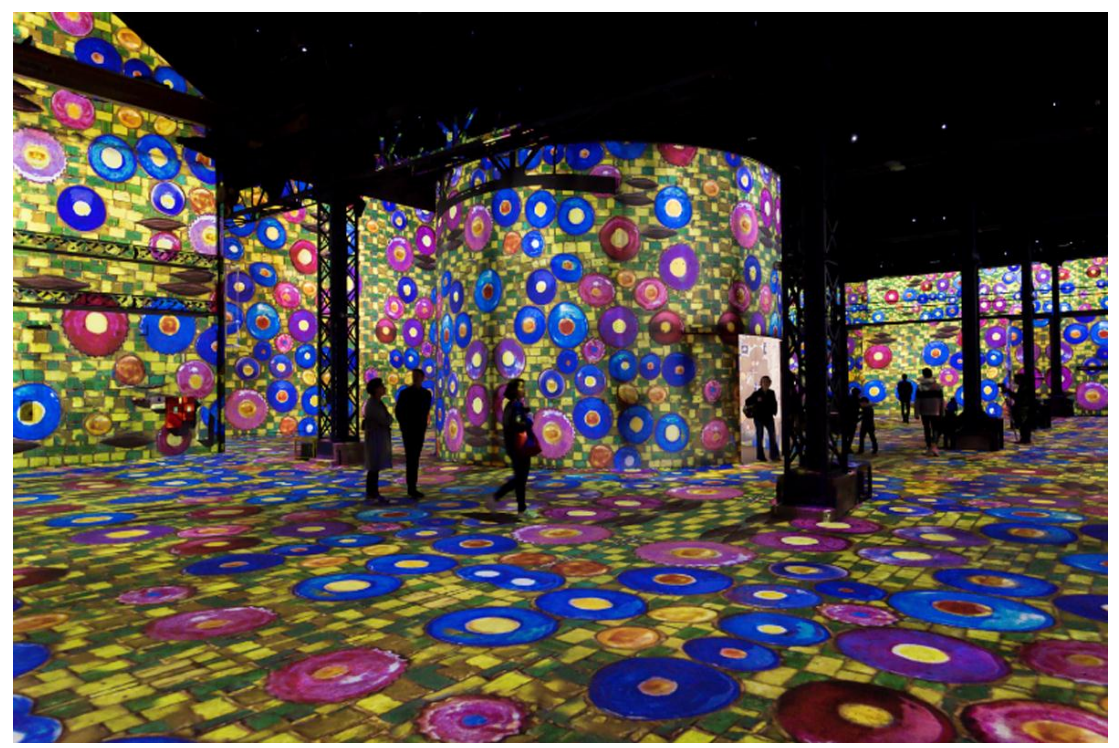

Figura 4: Vídeo Mapping na exposição do artista Gustav Klimt, "A explosão de Luz e cores" realizada em Paris.

Fonte: L'ATELIER DES LUMIÈRES, $2018^{2}$.

O vídeo mapping como ferramenta educativa pode apresentar: interação - a partir da ilusão de ótica; imersão - a partir da conexão com a obra e sensorialidade - som, cheiro e temperatura também são elementos que podem ser adicionados à experiência.

Tratando-se de uma ferramenta educativa, se faz necessário o planejamento prévio, observando que no processo de ensino/aprendizagem o recurso aplicado deve ter um propósito claro elaborado pelo professor. Assim sendo, nas próximas linhas estão traçados os aspectos metodológicos, apresentando o vídeo mapping como uma alternativa para o ensino de arte na Educação Inclusiva.

\section{A Escolha da Obra "Figurações Mapeadas" a partir das visualidades de Frida Kahlo}

A motivação para essa escolha ocorreu por meio da percepção das pinturas da artista Frida Kahlo, por serem retratadas suas dores em temas como: o casamento, a maternidade, a bissexualidade e o aborto. Também foi levado em consideração a artista apresentar deficiência - atrofia muscular. As obras selecionadas para a experiência foram: As duas Fridas (1939); Umas facadinhas de nada (1935); Árvore da esperança (1946), Minha babá e eu (1937), Hospital Henry Ford (1932) e Meu nascimento (1932).

\footnotetext{
${ }^{2}$ Disponível em: https://www.atelier-lumieres.com/fr/gustav-klimt. Acessado em 15 de Setembro de 2018.
}

Revista Digital do LAV - Santa Maria - vol. 14, n. 3, p. 67 - 82 - set./dez. 2021 ISSN 1983 - 7348 http://dx.doi.org/10.5902/1983734846865 
As obras foram selecionadas pelos pesquisadores, visando que os alunos sejam privilegiados para além das linguagens artísticas, além da experiência estética, mas também com as provocações a respeito da luta feminina acerca do respeito à sexualidade, gênero e contra o preconceito nos mais variados âmbitos da sociedade, instigando os discentes a refletirem e compreenderem a luta da mulher na sociedade, com uma perspectiva histórica, cultural e social.

A intenção da ferramenta é permitir ao sujeito uma reflexão acerca de uma narrativa histórica, neste caso em particular a sexualidade e o gênero feminino, a partir dessa experiência imersiva nas obras de Frida, indo além da visualidade comum na apreciação de obras de arte. Para a idealização da proposta imersiva se fez necessário a edição de vídeo.

Em seguida, a criação de objetos tridimensionais utilizando isopor para compor o ambiente servem como suporte para receber as criações editadas no computador. $O$ efeito tridimensional é criado a partir da relação entre estruturas utilizadas, espaços selecionados e o conjunto desses elementos com o vídeo mapeado.

Com relação a projeção, fizemos uso do Resolume Arena. O programa reproduz áudio e vídeo e aplica efeitos, permitindo a performance de acordo com a criação do artista. A figura 5 apresenta a montagem do cenário para a realização da instalação. $\mathrm{Na}$ figura 6, apresentamos a obra "figurações mapeadas", em que é possível uma visualização de seu processo de criação. Para a testagem da obra, utilizamos uma parede, quatro isopores, para garantir uma experiência tridimensional, e um data-show que projetou a criação mapeada do computador. Ressaltamos que essa experiência teve como objetivo validar tal processo criativo perante uma banca avaliativa.

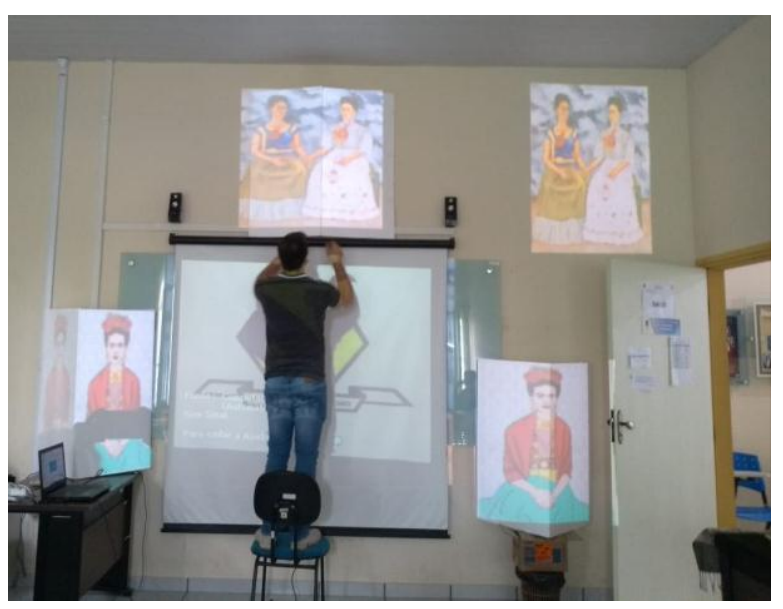

Figura 5: Montagem do cenário. Fonte: Elaborado pela autora, 2019.

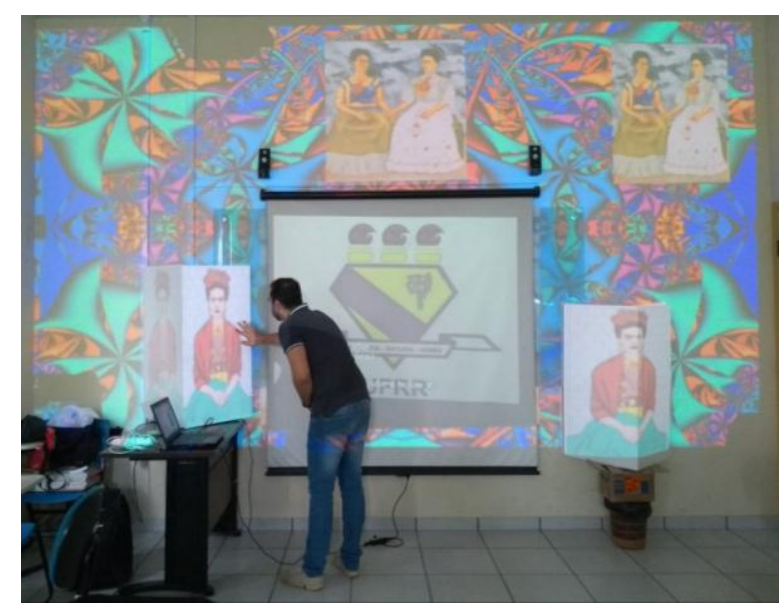

Figura 6: Obra - "figurações mapeadas". Fonte: Elaborado pela autora, 2019. 
A ferramenta audiovisual imersiva proposta para o ensino de Artes Visuais no campo da Educação Inclusiva, pretende proporcionar aos sujeitos da Educação Especial a possibilidade de leitura de imagens de uma maneira não convencional ao que geralmente é inserida nas aulas de Arte nas escolas de Educação Básica. A partir da ação, os alunos poderão se inspirar para a criação de imagens mentais. No caso dos alunos com deficiência visual, o olfato e a audição serão recursos para inserção e compreensão dessa atividade. Para os alunos Surdos, as imagens e o cheiro permitirão que eles se sintam imersos. Os alunos com deficiência física, deficiência intelectual e com transtorno do espectro autista (TEA) serão imersos pelos três sentidos - visão, audição e olfato.

A tecnologia apresentada reúne características que proporcionam diversas situações e contextos em um ambiente de aprendizagem divertido e eficaz. Segundo Braga (2001, p. s/n) cada indivíduo possui uma sensibilidade para o aprendizado, "uns visuais, outros verbais, uns gostam de explorar e outros preferem deduzir".

Nesta perspectiva, a utilização do vídeo mapping como experiência pode vir a promover ao aluno a aprendizagem de maneira lúdica e consistente. E ainda, a interação com os sujeitos, permitindo um olhar diferenciado no campo da Arte, como a visualização em alta qualidade das obras. Pode-se ainda promover estratégias de avaliação que sejam recorrentes as aulas realizadas com a discussão em torno das obras expostas, bem como uma reprodução após olhar a obra, que não necessariamente precisa ser desenhada, podendo também ser escrita, musicalizada, encenada, enfim, há uma infinidade de maneiras de reler uma obra de arte. A partir disso, será possível promover múltiplos olhares sobre a obra.

Os efeitos visuais em tempo real visam, nesta proposta, aguçar o processo criativo. Propomos, a partir das obras da artista, instigar os alunos a analisarem os elementos formais e questões subjetivas. O pensamento crítico será estimulado, estando atento ao seu 'olhar' ou percepção na leitura de imagens e na leitura de mundo a sua volta, visando a desnaturalização de gênero na sociedade.

\section{Considerações Finais}

O desafio da presente proposta se deteve em criar estratégias que possibilitassem novos modelos de aprendizagens para alunos com deficiência na perspectiva inclusiva, baseadas na sociedade da informação, consolidada na motivação entre professores e alunos de transformarem as potencialidades desses recursos em aprendizagem.

Revista Digital do LAV - Santa Maria - vol. 14, n. 3, p. 67 - 82 - set./dez. 2021 ISSN 1983 - 7348 http://dx.doi.org/10.5902/1983734846865 
Buscamos, com a realização deste estudo, promover a aprendizagem colaborativa, levando em consideração que trata-se de um recurso na área da educação que surge a partir da necessidade de inserir metodologias interativas entre o aluno ou usuário, em conjunto com o professor, para que estabeleçam buscas, compreensão e interpretação da informação de assuntos determinados.

$\mathrm{Na}$ aprendizagem colaborativa, há a construção do conhecimento de forma compartilhada pelos alunos a partir das trocas de informações, ajudas mútuas nas dificuldades encontradas, bem como na parceria entre aluno e professor, transformando o aluno em um sujeito autônomo no processo de ensino/aprendizagem.

As metodologias interativas, por sua vez, propõem a participação do aluno na realização das atividades, neste caso particular, nesta experiência. Esse formato metodológico permite a participação do aluno, e como consequência a aprendizagem se dá de modo ativo, é uma metodologia que pode ser integrada por meio das TIC, vetor desse processo e desta experiência.

Propomos, então, a imersão do aluno a partir da projeção de imagens, analisando como o vídeo mapping pode operar na produção do processo de ensino/aprendizagem de Artes Visuais de alunos com deficiência nas escolas públicas do estado de Roraima, por meio da Educação Inclusiva.

A partir das atividades a serem realizadas com esta proposta, buscamos permitir ao aluno o processo cooperativo e autônomo, promovendo a Educação Inclusiva; incentivamos a interação com a obra, de modo que o professor possa desenvolver atividades com possibilidades de baixo custo, acessibilidade e atratividade.

Percebemos que a inserção desta ferramenta no campo de ensino se mostra propícia, haja vista a promoção de experiência diferenciada, permitindo o uso das imagens cinematográficas, dialogando com novas expressões voltadas para o ensino de Arte.

Para além disso, são espaços que permitem 0 desenvolvimento do ensino/aprendizagem em vários níveis, dentre eles: emocional, cognitivo e socio-cultural. A interatividade que o espaço proporciona também é um atrativo para os alunos, fazendo com que as experiências não sejam apenas aulas 'chatas', mas um espaço lúdico e construtivo, e a partir disso, capaz de elevar o senso crítico e a expressão artística de cada um.

Revista Digital do LAV - Santa Maria - vol. 14, n. 3, p. 67 - 82 - set./dez. 2021 ISSN 1983 - 7348 http://dx.doi.org/10.5902/1983734846865 
Destacamos como desafio da presente proposta, criar estratégias que possibilitem novos modelos de aprendizagens, baseados na sociedade da informação, consolidando-se na motivação entre professores e alunos de transformarem as potencialidades desses recursos em aprendizagem.

Não obstante, cabe destacar que a inserção da arte para os alunos de Educação Especial na perspectiva da Educação Inclusiva ainda é uma barreira. Poderia ser diferente, afinal a arte é capaz de transformar o ser humano e levá-lo a novos horizontes. Entretanto, continua sendo usada simplesmente como um ato de distração.

Com o objetivo de propor uma reflexão referente ao ensino de arte no campo da Educação Especial na perspectiva inclusiva, apresentamos a proposta do vídeo mapping, que se mostra como uma abordagem diferenciada para as atividades, e busca imergir o aluno no campo das imagens, sons e efeitos sensoriais.

As tecnologias já se apresentam no campo da Educação Especial como uma alternativa. Em particular, no campo da arte não deve ser diferente, haja vista que promove ao aluno experiências inovadoras. A existência de diversas tecnologias disponíveis na escola - computador, data-show, caixa de som - bem como metodologias inovadoras para o ensino da arte são fundamentais no processo de ensinar. Todavia, tanto o professor quanto o aluno devem estar imersos na proposta, buscando alcançar o objetivo.

\section{Referências}

BARROSO, J. M. D.; ESCOLA, J. J. J. Filosofar com a Tecnologia Educativa. In: Escola. J. J. J.; RIVAS M. P. (Org.). As TIC no ensino: políticas, uso e realidade. Espanha: Andavira, 2011, p. 211-232.

BRAGA, M. Realidade Virtual e Educação. Revista de Biologia e Ciências da Terra, Volume 1, n. 01, p. s/n, 2001.

BRASIL. Constituição Federativa do Brasil de 1988. Brasília, 1988.

BRASIL. Lei no 9.394, de 20 de dezembro de 1996. Institui as diretrizes e bases da educação nacional. Brasília, 1996.

BRASIL. Ministério da Educação e Cultura. Diretrizes Nacionais para a Educação Especial na Educação Básica. Brasília, 1999.

BRASIL. Ministério da Ciência e Tecnologia Sociedade da Informação no Brasil: LIVRO VERDE. Brasília, 2000. 
BRASIL. Lei no 13.146, de 6 de julho de 2015. Institui a lei brasileira de inclusão da pessoa com deficiência (estatuto da pessoa com deficiência). Brasília, 2015. Disponível em: http://www.planalto.gov.br/ccivil_03/_ato20152018/2015/lei/l13146.htm. Acesso em: 26 set. 2017.

ESCOLA, J. J. Ensinar a aprender na sociedade do conhecimento. 40 SOPCOM, 2005, Aveiro. Livro de Actas do $4^{\circ}$ Congresso da Associação Portuguesa de Ciências da Comunicação. Universidade de Aveiro, 2005, p. 343-358.

GARCIA, R. de O. Video mapping: um estudo teórico e prático sobre projeção mapeada. 2014. Trabalho de Conclusão de Curso (Bacharel em Comunicação Social - habilitação em Radialismo) - Universidade Estadual Paulista, Faculdade de Arquitetura, Artes e Comunicação, 2014.2 Disponível em: https://repositorio.unesp.br/handle/11449/119214?locale-attribute=es. Acesso em: 08 nov. 2018.

HOUSEN, A. O olhar do observador: investigação, teoria e prática. In: FRÓIS, J. P. (Org.). Educação estética e artística: abordagens transdisciplinares. Lisboa: Fundação Calouste Gulbenkian, 2000, p. 147-168.

LEMOS, C.; SILVA, L. R. A Música como uma Prática Inclusiva na Educação. In: Revista do Núcleo de Estudos e Pesquisas Interdisciplinares em Musicoterapia, Curitiba, v. 2, p. 32-46, 2011.

LIMA, F. R. B.; SANTOS, P. L. V. A. da C. Caderno de Artista em Ambiente Digital. In: Baleia na Rede, Revista online do Grupo Pesquisa em Cinema e Literatura. UNESP, Vol. 1, no 6, p. 402-415, Ano VI, Dez/2009.

MORAES, W. L. VIDEO MAPPING: inquietações para uma poética. 2014. Dissertação (Mestrado em Arte e Cultura Visual) - Universidade Federal de Goiás, Goiânia, 2014. Disponível em: https://repositorio.bc.ufg.br/tede/handle/tede/4681. Acesso em: 20 de abr de 2019.

MOREIRA, M. A. A teoria da aprendizagem significativa e sua implementação em sala de aula. Brasília: Editora Universidade de Brasília, 2006.

PAIM, J. F. B. Paisagens Fílmicas: Um diálogo Possível entre Vídeo, Corpo, Tempo e Espaço. 2011. Dissertação (Mestrado em Artes Visuais) - Universidade Federal da Bahia (UFBA), Salvador, 2011. Disponível em: https://repositorio.ufba.br/ri/handle/ri/9827. Acesso em: 20 mai. 2020.

POSCA, L. M. Criação de material de apoio para o ensino básico de artes visuais para alunos deficientes visuais. 2017. Dissertação (Mestrado em Artes) Universidade Federal de Uberlândia (UFU), Uberlândia, 2017. Disponível em: http://repositorio.ufu.br/handle/123456789/19445. Acesso em: 12 de abr de 2019.

PRENSKY, Marc. Digital Natives, Digital Immigrants. In: PRENSKY, Marc (orgs.). On the Horizon. MCB University Press, v. 9, n. 5, p. 2-6, out. 2001.

\footnotetext{
Mestre em Educação - Comunicação e Tecnologias Educativas pela Universidade de Trás-os-Montes e alto Douro; Especialista em Educação Especial na Perspectiva da Educação Inclusiva e Graduada em Licenciatura em Informática pela Universidade Federal de Roraima (UFRR). Estudante-Pesquisadora dos grupos de Pesquisa AMA[Z]OOM - Observatório Cultural da Amazônia e do Caribe. Experiência em coordenação de
}

Revista Digital do LAV - Santa Maria - vol. 14, n. 3, p. 67 - 82 - set./dez. 2021 ISSN 1983 - 7348 http://dx.doi.org/10.5902/1983734846865 
projetos sociais. Colaborei como professora do Instituto Insikiran de Formação Superior Indígena da UFRR (semestre 2019.1). Atualmente atuando no Projeto de Pesquisa Mosaico Digital: Imbricações entre Arte e Tecnologia, Consumo Cultural e Midiático Juvenil no Estado de Roraima. Desenvolvo pesquisa nas áreas de Arte e Tecnologia, Economia Solidária e Educação a Distância. Áreas de interesse: Tecnologias da Informação e Comunicação; Arte e Tecnologia; Educação Inclusiva e Economia Solidária.

ii É doutorando em Artes Visuais pela Universidade de Brasília ? UNB, DF (2019), mestre em Artes pela Universidade Federal de Uberlândia ? UFU, MG (2017), especialista em Arte-Educação pelo Claretiano, SP (2012) e licenciado em Artes Visuais pelo Centro Universitário Moura Lacerda ? CUML, SP (2009). Atua como Professor efetivo no curso de Licenciatura em Artes Visuais da Universidade Federal de Roraima - UFRR trabalhando nas frentes de Escultura, Tridimensionalidade, Ensino de Arte e Criatividade. Como artista, atualmente tem realizado investigações na linguagem tridimensional. Possui experiência em Artes Visuais e Arte Educação. Trouxe para o ensino superior a experiência adquirida em quase dez anos de atuação no Ensino de Arte em todos os seguimentos da Educação Básica, coordenou a versão do Programa Institucional de Bolsa de Iniciação à Docência - PIBID Artes Visuais da UFRR nos anos de 2018-2019. Atualmente, desenvolve pesquisas na linha de Imagens, Visualidades e Urbanidades, especificamente sobre os imaginários urbanos nas cidades de Boa Vista-RR e Brasília-DF. Desenvolveu também trabalhos sobre o Ensino de Arte, Formação de Professores e o uso das tecnologias para a Inclusão nas Artes Visuais.

iii Bacharel e Licenciado em Ciências Biológicas pela Universidade Federal de São Carlos UFSCar (1992); Especialização em Zoologia pela Universidade Estadual Paulista - UNESP Campus de Rio Claro/SP(1993); Mestre em Ecologia (1997) e Doutor em Ciências (2002) pelo PPG em Ecologia e Recursos Naturais da UFSCar; Pós-Doutorado no Laboratório de Planejamento Ambiental da UFSCar em (2012) com Ensino de Ecologia e Educação Ambiental. Lecionou entre 2006 a 2015 do curso de Lic. Ciências Biológicas da Universidade Federal de Sergipe (Campus Itabaiana). Atualmente é professor Associado I da Universidade Federal de Roraima (UFRR) do curso de Lic. em Educação do Campo/LEDUCAR da UFRR. Professor colaborador do PPG-Geografia/UFRR e efetivo do PPG Profissional Profágua. Coordenador de Tecnologias Sociais (Portaria n.001/2018 ? PRAE de 11 de janeiro de 2018) da ITCPES/UFRR.

Como citar esse artigo:

NASCIMENTO, Cleane da Silva; POSCA, Luís Müller; MARIOTI, Paulo Sérgio. Experiência Multissensorial: Uma Proposta para Alunos com Deficiência na Perspectiva da Educação Inclusiva. Revista Digital do LAV, Santa Maria: UFSM, v. 14, n. 3, p. 67-82, set./dez. 2021.

Revista Digital do LAV - Santa Maria - vol. 14, n. 3, p. 67 - 82 - set./dez. 2021 ISSN 1983 - 7348 http://dx.doi.org/10.5902/1983734846865 